\title{
Genotype by Environment Interaction by AMMI and GGE Bi-Plot Analysis for Maize (Zea Mays $L$.) for Transitional High Land Agroecology of Ethiopia.
}

\section{Gemechu Getachew ( $\square$ gamechu85@gmail.com )}

Ethiopian Institute of Agricultural Research

\section{Beyene Abebe}

Ethiopian Institute of Agricultural Research

\section{Deselegn Chelchisa}

Ethiopian Institute of Agricultural Research

Sara Oli

Ethiopian Institute of Agricultural Research

\section{Temesgen Chebsa}

Ethiopian Institute of Agricultural Research

\section{Zelalem Tefa}

Ethiopian Institute of Agricultural Research

\section{Bedlu Guban}

Ethiopian Institute of Agricultural Research

\section{Abu Ngozi}

University of Nigeria

\section{Research Article}

Keywords: AMMI, Genotype by Environment, GGE-biplot, Zea mays.

Posted Date: August 12th, 2021

DOl: https://doi.org/10.21203/rs.3.rs-589678/v1

License: (a) (i) This work is licensed under a Creative Commons Attribution 4.0 International License. Read Full License 


\section{Abstract}

The current research examined the magnitude of genotype by environment interaction ( $G \times E)$ and evaluated the adaptability and stability of maize genotypes for grain yield in Ethiopia's transitional highland agroecology using an additive main effects and multiplicative interaction (AMMI) model. The study's goals were to first assess the yield output and stability of maize genotypes in Ethiopia's transitional highlands, and then to investigate the effect of genotype- environment interaction on genotype yield. During the main season of 2017/2018, thirteen advanced maize genotypes which was selected from different observation trials with two commercial check hybrids were evaluated at five representative locations for agroecology. The experiment was set up using an alpha lattice $(3 * 5)$ with three replications and two rows per plot. AMMI showed highly significant $(P<0.001)$ variation of grain yield was observed due to the effect of genotype $(G)$, Environment(E) and their interaction ( $\mathrm{G} \times \mathrm{E})$. In fact, all genotypes evaluated in representative locations for this agroecology had higher grain yield advantages than the best commercial check except one genotype. Overall, this study discovered the possibility of fast releasing and overtake of new maize hybrids for transitional high land agroecology of Ethiopia to exploits availability maize germplasm to maximize production. The best candidate genotype, MABK181261 is a stable and high-yielding product. It is recommended for release as a commercial hybrid alternative after national variety verification trial in a high land transitional agroecology of Ethiopia. In addition, the parental lines of this genotypes can be used to enhance germplasm of opposite heterotic group in maize breeding for East Africa.

\section{Background}

Maize is one of the stable crops that millions of Ethiopians depend on for their daily calories. It grows from the lowlands to the highlands in the agroecology of the country. Ethiopian farmers have used several commercial corn hybrids developed and released by National Maize Breeding Research, such as BH540, BH546 and BH547 for low to mid-altitudes and BH660 and BH661 for transitional highlands. Selecting superior and stable hybrids from advanced variety trials planted in multiple locations is critical to the agroecology of the transitional highlands of Ethiopia. The performance of genotypes varies in all environments, especially in tropical regions with high seasonal and spatial variability [1-3], is referred to as genotype by environment interaction. Experiments in single environment (location) do not cause general conclusions to be drawn about the genotypes being studied. As a result, multi-environment trials are required to identify a dependable and superior hybrid. Therefore, the general strategy of the testing trial in year-by-locations representing agroecological conditions rather than multiple tests combined year after year [4,5]. When genotypes rank differently in different environments (locations and/or years), G x E interaction is important from the standpoint of breeders. The stability of suitable genetic characters is critical for producing improved varieties that can be used commercially under a wide range of agroclimatic conditions. The evaluation of genotypes for the $\mathrm{G} \times \mathrm{E}$ provides useful information on their behavior in specific environments $[6,8]$. Therefore, each genotype responds differently to changing climate and soil conditions; some have higher $\mathrm{G} \times \mathrm{E}$ interactions, while others have lower interactions. The main task of maize breeders is to select superior genotypes for narrow or broad adaptation, and to determine the best experimental sites that can be used to select excellent and stable genotypes [5, 7]. As a result, yield stability and superiority of maize genotypes evaluated in different environments can help breeders develop superior hybrid. The additive main effects and multiplicative interaction models are frequently used for data analysis to sort out statically significant different within genotype, Environment, and their interaction ( $\mathrm{G} \times \mathrm{E}$ ) to select superior and stable genotype [4, 9]. The primary goals of this study were to (1) evaluate the yield performance and stability of maize genotypes for Ethiopia's transitional high land, and (2) investigate the influence of genotype by environment interaction on genotype yield.

\section{Materials And Methods}

\subsection{Germplasm used and Description of locations}

Thirteen advanced maize genotypes which was selected from different observation trials with two commercial check hybrids were used. Seeds for 13 genotypes and 2 commercial checks maize hybrids were produced at nursery of breeding blocking through hand pollination at Bako National Maize Research Center (Table 1). The experiment was evaluated at five environments vs Bako, Arsi negele, Haramaya, Pawe and F/Selam (Table 2 and Figure 1). Environments are representative for maize growing area of transitional highland altitude agroecology of Ethiopia.

Table 1 description of maize genotypes used over five locations for this experiment. After the "Table 1" 


\begin{tabular}{|llll|}
\hline Entry & Genotype name & Pedigree name & Source \\
\hline 1 & MABK181250 & BKL004/124-b (109)//144-7b & BNMRC \\
\hline 2 & MABK181251 & BKL003/BKL004//144-7b & $>>$ \\
\hline 4 & MABK181252 & BKL003/BKL004//143-5-i & $>>$ \\
\hline 5 & MABK181253 & CML395/30V53F2-20-2-1-2//142-1-e & $>>$ \\
\hline 6 & MABK181254 & CML395/30V53F2-20-2-1-2//144-7b & $>>$ \\
\hline 7 & MABK181256 & BKL004/BKL002//144-7b & $>>$ \\
\hline 8 & MABK181257 & BKL004/BKL002//143-5-i & $>>$ \\
\hline 9 & MABK181258 & CML444/CML536//142-1-e & $>$ \\
\hline 10 & MABK181259 & CML444/CML536//144-7b & $>$ \\
\hline 11 & MABK181260 & CML444/CML536//143-5-i & $>$ \\
\hline 12 & MABK181261 & BKL004/CML536//142-1-e & $>$ \\
\hline 13 & MABK181262 & BKL004/CML536//143-5-i & $>$ \\
\hline 14 & BH660 (S Check) & A7033/F7215//142-1-e & $>>$ \\
\hline 15 & BH661 (S check) & CML395/CML202/142-1-e & $>>$ \\
\hline
\end{tabular}

BNMR =Bako National Maize Research Center, $\mathrm{S}$ Check = Standard check (commercial check)

Table 2 description of environments and geographical coordinate used to evaluate genotypes [26-28]. After "Table 2"

\begin{tabular}{lllllllll} 
Environment & Lati $(\mathrm{N})$ & Long $(\mathrm{E})$ & Alti & $\mathrm{RF}(\mathrm{mm})$ & \multicolumn{2}{l}{ Temperature $\left({ }^{\circ} \mathrm{C}\right)$} & SMgt & ST \\
\hline Bako & $9^{\circ} 06^{\prime}$ & $37^{\circ} 09^{\prime}$ & & & Max & Min & & \\
\hline Arsi-Negele & $7^{\circ} 20^{\prime}$ & $38^{\circ} 9^{\prime}$ & 1650 & 1598 & 29 & 12.78 & opt & Nitisol \\
\hline Pawe & $11^{\circ} 19^{\prime}$ & $36^{\circ} 24^{\prime}$ & 1960 & 866 & 26 & 9.1 & opt & Andosol \\
\hline F/Selam & $10^{\circ} 42^{\prime}$ & $37^{\circ} 16^{\prime}$ & 1120 & $1000-1500$ & 32.6 & 16.5 & opt & Nitisol \\
\hline Haramaya & $9^{\circ} 24^{\prime}$ & $42^{\circ} 1^{\prime}$ & 1935 & 1125 & 26 & 13.5 & opt & Nitisol \\
\hline
\end{tabular}

Lati $=$ Latitude, Long $=$ Longitude, Alti= Altitude $(m . a . s l), R F=$ Annual rain fall, SMgt $=$ Soil Management, $S T=$ Soil type

\subsection{Experimental management}

Genotypes were planted in $5.1 \mathrm{~m}$ long two-row plots with $0.75 \mathrm{~m}$ between rows and $0.25 \mathrm{~m}$ between plants. At the planting and flowing stages, the recommended NPS was applied. Also, pre-emergency herbicide (Grama Gold) was applied to control weeds. When it's appropriate, hand weeding rehearsals are conducted. The experiment was carried out during the rainy season.

\subsection{Experimental design and statically analysis}

The experimental design used was alpha lattice $(3 \times 5)$ with three replications with two rows per plot for each location. Software available online http://www.pbstat.com/ "PBSTAT-GE" was used for data analysis. Environments were treated as a random effect in the combined analysis, whereas genotypes were treated as a fixed effect. Least square means were simultaneously generated for AMMI model. Following single site ANOVA for grain yield, the combined ANOVA and AMMI analysis of variance were done for $G, G \times E$ and $G \times$ E interaction [10-11]. The following formula used to estimate yield of genotype, environment and G X E interaction through stability analysis using AMMI analysis model [12] as follow 
$Y g e=\mu+\alpha g+\beta e+\alpha \sum_{n=1}^{N} \lambda n^{y} g n^{y} e n+\theta g e$

Whereas $\mathrm{Yge}=\mathrm{GY}$ of genotype, $\mathrm{e}=$ environment, $\mu=$ the grand mean; $\mathrm{ag}=$ genotype mean deviation; $\beta \mathrm{e}=$ environment mean deviation; $\mathrm{kn}=$ Eigen value of the principal component (PCA) axis, cgn and gen = the genotype and environment PCA scores for the PCA axis, $n N=$ number of PCA axes retained in the model and hge = residual.

\section{Data collected}

According to Getachew [13], data on grain yield and other important agronomic traits are collected as follows:
(1) Grain weight (t/ha
(2) Actual moisture content
(3) Days to anthesis
(4) Days to silking
(5) Plant aspects
(6) Ear aspects
(7) Ear height (cm)
(8) Plant height (cm)

\section{Result And Discussion}

\subsection{AMMI analysis}

The combined AMMI showed highly significant differences $(P<00.1)$ across environments for environment, genotypes, genotype by environment, and genotype by environment interaction (Table 4). AMMI revealed that there was a significant $\mathrm{G} \times \mathrm{E}$ for grain yields. This highlights the importance of thoroughly testing these cultivars in a multi-environment before recommending them to farmers. This result strongly supports the findings reported by other authors, which have important implications for the grain yield of maize grown in multiple environments $[5,14,15$ and 16$]$. The test environment accounted for 55.78 percent of total variation in grain yield, with genotype accounting for 7.88 percent and $\mathrm{G} \times \mathrm{E}$ accounting for 14.55 percent, indicating that environmental main effects outweighed genotypic main effects. The magnitude sum of squares of $\mathrm{G} \times \mathrm{E}$ is greater than that of genotype effects, indicating that there are more differences in genotypic response across environments. Many researchers $[5,11,15$ and 17] have reported that the environment has a significant impact on yield stability. The multiplicative effects analysis (Table 4) revealed that the AMMI model with test environment contributed 55.78 percent of the total variation of sum square for grain yield, while $G$ and $G \times$ E sources of variation accounted for 7.88 percent and 14.55 percent, respectively. Other research has found that in multi-environment trials, location accounts for the vast majority of total variation, with genotype and $\mathrm{G} \times \mathrm{E}$ accounting for only a minor portion $[4,5,15]$.

\section{Table 3 AMMI analysis for grain yield. After "Table 3"}

\begin{tabular}{|lllllll|}
\hline Source of Variation & $\mathrm{df}$ & Sum of squares & Mean Squeres & Total variation explained \% & G x E explained\% & Probability \\
\hline ENV & 4 & 767.45 & $191.86^{\star \star}$ & 55.78 & - & 0.0001 \\
\hline GEN & 14 & 108.45 & $7.74^{\star \star}$ & 7.88 & - & 0.00001 \\
\hline G $~$ & $3.57^{\star \star}$ & 14.55 & - & 0.01 \\
\hline IPCA1 & 56 & 200.19 & $8.06^{\star \star}$ & - & 68.4 & 0.00001 \\
\hline IPCA2 & 17 & 137.01 & $2.11^{\text {ns }}$ & - & 15.8 & 0.34 \\
\hline IPCA3 & 15 & 31.70 & $1.74^{\text {ns }}$ & - & 11.3 & 0.530 \\
\hline IPCA4 & 13 & 22.63 & $0.80^{\text {ns }}$ & - & 4.40 & 0.94 \\
\hline IPCA5 & 11 & 8.85 & $0^{\text {ns }}$ & - & - & 1 \\
\hline Residuals & 9 & 0 & 1.99 & 21.79 & - & NA \\
\hline
\end{tabular}

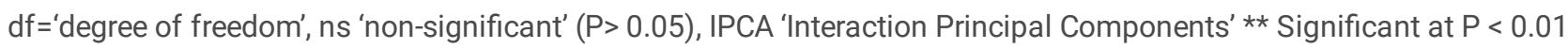

\subsection{Performance of genotype in specific environment and mult-enviromnent}


In Table 4, AMMI revealed that the first two hybrids (G11, G12) were the best performers in each environment, while CK1 was the worst

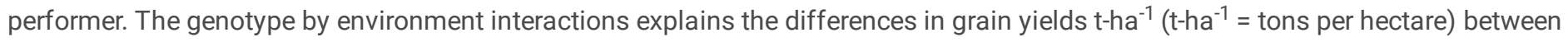
selected genotypes in five environments. This is also referred to as crossover genotype by environment interaction $[4,5,15=18,16=19$, 13=17 and 17=20]. Bako 10.63 t-ha-1 (MABK181259), A/ Negele 9.04 t-ha $^{-1}$ (MABK181255), Pawe 6.62 t-ha $^{-1}$ (MABK181261), F/selam10.3 t-ha ${ }^{-1}$ (MABK181262), and Haromaya 7.43 t-ha $^{-1}$ (MABK181259) were the highest yielders for each individual location. However, BH660 (check1) produced the lowest yielder for five individual locations: Bako (5.52 t-ha-1 ), A/Nagel (4.41 t-ha-1), Pawe (3.51 t$\left.\mathrm{ha}^{-1}\right)$, F/Selam (4.87 t-ha-1) and Haromaya (3.6 t-ha-1). The average grain yield for all genotypes evaluated in multi-environment was higher than the best commercial check (BH661), with the exception of MABK181254. This implies possibility of fast releasing and overtake of new maize hybrids for transitional high land agroecology of Ethiopia to exploits available of maize inbred line germplasm to maximize production and productivity. Wender [21] also reported similar result that grain yield of some hybrids evaluated over location was higher than grain yield of commercial check. From total studied genotypes, seven genotypes had more than grand mean (6.55 $\mathrm{t}^{-h} \mathrm{a}^{-1}$ ) of grain yield. This study approves Legesse [14] which the grain yield of maize genotype varied based on the interactions of genotypes $x$ environments within across test environments. Based on IPCA1 scores, genotype MABK181251, MABK181252, MABK181257, MABK181259, MABK181260 and MABK181262 had negative interaction with the environment, in opposite direction genotype MABK181250, MABK181253, MABK181254, MABK181255, MABK181256, BH660 and BH661 had positive interaction with environment in Table 5. Genotype MABK181255 (0.66) had highest positive interaction with environment whereas, genotype MABK181261 (0.13) had the lowest positive interaction. Relatively, the lowest and the highest negative interaction with environment expressed from MABK181259 (-1) and MABK181257 (-0.05) respectively. Genotype MABK181257, MABK181258, MABK181259 and MABK181262 had negative interaction with environment for both IPCA1 and IPCA2. However, genotype MABK181250, MABK181254, MABK181256, BH660 and BH661 had positive interaction with for IPCA and IPCA2. In AMMI analysis, positive interactions of IPCA scores of genotypes indicate environmental stability. These genotypes that exhibit a high degree of positive interaction with the environment can make use of the specific agro-ecological conditions of the environment to better adapt to these environments [18-19].

Table 4 Grain yield mean Performance for Individual location and all studied traits multi-environment 


\begin{tabular}{|c|c|c|c|c|c|c|c|c|c|c|c|c|}
\hline \multirow{2}{*}{$\begin{array}{l}\text { Genotype } \\
\text { name }\end{array}$} & \multicolumn{5}{|c|}{ Individual location for $G Y^{t-h 1}$} & \multicolumn{7}{|c|}{ Across locations for all traits } \\
\hline & BAKO & $\begin{array}{l}\text { ARSI } \\
\text { NEGELE }\end{array}$ & PAWE & F/SELAM & HARAMAYA & $\begin{array}{l}\mathrm{GY}{ }^{\mathrm{t}} \\
\mathrm{h} 1\end{array}$ & $A D$ & SD & $\mathrm{PH}$ & $\mathrm{EH}$ & EA & PA \\
\hline MABK181250 & 8.18 & 6.49 & 5.96 & 5.68 & 6.55 & 6.57 & 89.07 & 93.64 & 276 & 155.4 & 2.17 & 2.56 \\
\hline MABK181251 & 9.04 & 5.3 & 5.38 & 7.44 & 4.71 & 6.37 & 89.65 & 93.87 & 280.5 & 155.6 & 2.42 & 2.41 \\
\hline MABK181252 & 7.77 & 5.35 & 5.14 & 8.14 & 5.11 & 6.3 & 90.07 & 93.89 & 275.4 & 161.3 & 2.5 & 2.53 \\
\hline MABK181253 & 7.56 & 7.11 & 3.77 & 6.72 & 6.25 & 6.28 & 90.03 & 93.99 & 266.2 & 151.4 & 2.25 & 2.48 \\
\hline MABK181254 & 4.77 & 5.47 & 5.03 & 6.19 & 4.57 & 5.21 & 90.07 & 94.1 & 271.9 & 155.6 & 2.38 & 2.46 \\
\hline MABK181255 & 7.34 & 9.04 & 4.07 & 6.53 & 4.37 & 6.27 & 89.41 & 93.67 & 280.7 & 175.2 & 2.58 & 2.61 \\
\hline MABK181256 & 7.39 & 7.71 & 5.34 & 7.34 & 6.81 & 6.92 & 88.98 & 93.53 & 266.9 & 159.5 & 2.5 & 2.51 \\
\hline MABK181257 & 8.82 & 6.75 & 3.83 & 7.29 & 5.39 & 6.42 & 89.17 & 93.43 & 275.5 & 161 & 2.38 & 2.56 \\
\hline MABK181258 & 9.2 & 5.84 & 5.21 & 8.11 & 6.43 & 6.96 & 89.41 & 93.69 & 269.1 & 165 & 2.5 & 2.38 \\
\hline MABK181259 & 10.63 & 4.41 & 4.61 & 9.42 & 7.43 & 7.3 & 89.93 & 93.89 & 270.7 & 151.1 & 2.17 & 2.38 \\
\hline MABK181260 & 9.18 & 5.61 & 5.31 & 8.4 & 7.34 & 7.17 & 89.6 & 93.64 & 275.4 & 153.9 & 2.46 & 2.41 \\
\hline MABK181261 & 9.44 & 8.22 & 6.62 & 7.99 & 6.65 & 7.78 & 89.65 & 93.57 & 273.3 & 160 & 2.54 & 2.51 \\
\hline MABK181262 & 9.09 & 6.98 & 5.57 & 10.3 & 6.93 & 7.77 & 89.26 & 93.5 & 267 & 154.7 & 2.13 & 2.48 \\
\hline $\begin{array}{l}\text { BH660 (S } \\
\text { Check) }\end{array}$ & 5.57 & 7.07 & 3.51 & 4.86 & 3.6 & 4.92 & 90.79 & 94.08 & 265 & 158.1 & 2.42 & 2.75 \\
\hline $\begin{array}{l}\text { BH661 (S } \\
\text { check) }\end{array}$ & 6.94 & 7.88 & 4.15 & 5.41 & 5.51 & 5.98 & 89.36 & 93.67 & 274.8 & 155.4 & 2.46 & 2.73 \\
\hline MEAN & 8.06 & 6.62 & 4.9 & 7.32 & 5.84 & 6.55 & 89.63 & 93.74 & 272.5 & 158.2 & 2.39 & 2.51 \\
\hline MAX & 10.63 & 9.04 & 6.62 & 10.3 & 7.43 & 7.78 & 90.79 & 94.08 & & & 2.42 & 2.75 \\
\hline MIN & 5.57 & 4.41 & 3.51 & 4.86 & 3.6 & 4.92 & 88.98 & 93.53 & 266.9 & 5 & 2.5 & 2.51 \\
\hline LSD 0.05 & 3.05 & 1.63 & 2.13 & 1.8 & 0.92 & 0.88 & & & & & & \\
\hline CV (\%) & 33.24 & 14.58 & 20.9 & 22.19 & 13.54 & 22.32 & & & & & & \\
\hline
\end{tabular}

$\mathrm{GY}=$ grain yield, $\mathrm{AD}=$ anthesis date $\mathrm{SD}=$ silking date, $\mathrm{PH}=$ plant height, $\mathrm{EH}=$ ear height $\mathrm{EA}=$ ear aspect $\mathrm{PA}=$ plant aspect

Table 5 AMMI adjusted mean grain yield (t-ha ${ }^{1}$ ) IPCA score of genotypes and ASV of 15 genotypes tested across five environments in Ethiopia. After "Table 5". 


\begin{tabular}{|lllll|}
\hline Genotype name & $\begin{array}{l}\text { Mean GY } \\
\left.\text { (t-ha }{ }^{1}\right)\end{array}$ & IPCA1 & IPCA2 & ASV \\
\hline MABK181250 & 5.92 & 0.18 & 0.30 & -0.71 \\
\hline MABK181251 & 5.90 & -0.40 & 0.07 & -0.31 \\
\hline MABK181252 & 5.79 & -0.33 & 0.29 & 0.21 \\
\hline MABK181253 & 5.66 & 0.22 & -0.27 & 0.09 \\
\hline MABK181254 & 4.75 & 0.27 & 0.85 & 0.29 \\
\hline MABK181255 & 5.83 & 0.66 & -0.47 & 0.23 \\
\hline MABK181256 & 6.24 & 0.32 & 0.15 & 0.16 \\
\hline MABK181257 & 5.88 & -0.08 & -0.49 & -0.02 \\
\hline MABK181258 & 6.31 & -0.38 & -0.02 & -0.11 \\
\hline MABK181259 & 6.56 & -1.00 & -0.25 & -0.06 \\
\hline MABK181260 & 6.43 & -0.45 & 0.07 & -0.06 \\
\hline MABK181261 & 7.12 & 0.13 & -0.01 & -0.21 \\
\hline MABK181262 & 7.08 & -0.38 & -0.02 & 0.64 \\
\hline BH660 (S Check) & 4.56 & 0.64 & -0.01 & 0.03 \\
\hline BH661 (S check) & 5.43 & 0.61 & -0.17 & -0.16 \\
\hline 1(Bako) & 8.06 & -0.55 & -0.50 & -0.43 \\
\hline 3(Arsi Negele) & 6.61 & 1.00 & -0.32 & 0.14 \\
\hline 4(Pawe) & 4.89 & 0.08 & 0.64 & -0.25 \\
\hline 5(F/Selam) & 7.32 & -0.57 & 0.02 & 0.62 \\
\hline 6(Haramaya) & 2.92 & 0.05 & 0.15 & -0.08 \\
\hline
\end{tabular}

\subsection{GGE Biplot analysis}

The GGE biplot can be thought of as a graphical representation of matrix multiplication. As a result, fifteen hybrids, including two commercial checks, were evaluated at the five sites shown in Figures 2, 3, 4, and 5. GGE biplot analysis gathered a lot of useful information from various biplot graphs [4, 5 and 15]. The $x$-axis was the first principal component (PC1) scores, and the $y$-axis was the second principal component (PC2) scores. Biplot's total variation in relation to $\mathrm{G}$ and GEl explained 80.1 percent of the variance (Figure 2).

PC1 explained 65.4 percent of genotype by GGE from total variation, while PC2 explained 14.7 percent. Two principal components (PC1 \& PC2) explained more than half of the $G \times E$ interpretation. Therefore, the first two PCs can be used to predict the best AMMI model to explain the two interpretable modes which supported finding of Yan \& Tinker [20] and Yan [21]. The GGE biplot is shown in Figure 4, in which the environments are connected to the biplot origin vs the vectors. This perspective aids in comprehending the environment's interrelationships. According to Yan [22], the vector length close to the standard deviation in each test environment is a measure of the environment's ability to distinguish genotypes. As a result, the F/Selam's vector is abnormally short in comparison to the plot size. Therefore, predicted genotype differences based on vectors from such environments may not be reliable and only reflect noise. The polygon view of the GGE biplot is useful for visualizing the multi-environment trial dataset's "which-won-where" pattern. PC1 accounted for 62.7 percent of variation, while PC2 accounted for 17.5 percent (Figure 5). Demisew [15], Hortense [23] and Legesse [14] also reported the variation of PC1 was much greater than PC2 in their studies of maize hybrids. Grain yield was explained by 80.4 percent of total variation on both axes. Draw vertical lines on each side of the polygon starting at the biplot origin. As shown in Figure 5, the rays of the two-line graphs divide the graph into six parts, with five environments appearing in one sector and the remaining environments appearing in another. The sectors had different high yielding vertex genotypes, such as MABK181261, MABK181255, MABK181253, MABK181254, 
MABK181259, and MABK181262, which are located at the polygon's corner and have the longest vectors. In comparison to other hybrids, these genotypes were among the most responsive to the environments in their respective directions. When a test environment is divided into mega Environments, it means that different environments have different high yielding genotypes for those sectors, indicating crossover $\mathrm{G}$ x E [24]. Based on this, the polygon views divided the test environment into three mega environments, with Bako, Pawe and Haromaya in best genotype MABK181262 group I, F/Selam MABK181259 group II and A/Negele in best genotype 6 (group III). Eliyas [16] also used GGE-biplot models and classified eight environments into two mega-environments for sugar cane genotypes evaluation for yield. To avoid random GEl, genotype evaluation in mega environment should be based on both mean performance and stability [25]. As a result, the genotypes MABK181261 and MABK181262 were identified as high yielders in the AMMI analysis. However, MABK181261 was identified as stable. only MABK181261 was chosen as the ideal genotype because it met both of the criteria. Demissew [15] also selected three maize hybrids for high land mid altitude of Ethiopia using the same criteria. Genotype MABK181262 is the highest yielding vertex hybrid in all the test environments that share the sector with it. Whereas MABK181259 was the highest yielding found in separate sector at $\mathrm{F} /$ selam site.

The environment -vector view of the GGE biplot with the average -environment axis was shown in Figure 3. A test environment with a smaller angle with average environmental axis is the most representative of the others. Thus, Pawe's vector is very short, ensuring that all genotypes perform similarly. Consequently, it no information or gave little information about genotype difference [4 and 14]. According to Yan [22] the biplot's concentric circles aid in visualizing the length of the environment vectors. This is a measure of the environments' discriminating ability and representativeness that is proportional to the standard deviation of each environment Bako has long vectors and small angles, and when combined with absicca, which is more discriminating genotypes and representative of test environments, the result is ideal for genotype selection. Through discriminating and representativeness by GGE biplot analysis, testing environments were used to distinguish environments that select high yielder genotypes in sets of environments. A/NEGEL has a long vector with a large angle as the result it cannot be used to select genotype.

performing genotypes, but it can provide information on genotypes that are unstable [24]. The discriminating test environments of A/NEGEL and F/SELAM are not representative, but they are useful for selecting specific adapted genotypes and discarding unstable genotypes. The performance of genotypes can be easily identified in a test environment with high representativeness and discriminating ability [21]. Only one test environment (Bako) is both representative and discriminating, making it a good place to find genotypes that are generally adapted. Similar results as many authors Y Matana [4]; SALEEM [26], Dagnechew [27], Ndlala [28], Dao [29] and Moges [30], who used GGE biplot to identify high representativeness and discriminating for different crops.

\subsection{Stability of genotype}

The stability of maize genotypes and average grain yield in all environments should be assessed within a single mega environment. Figure 4 shows the stability and average performance of the evaluation genotype. According to Yan [21], the AEC abscissa is a single arrowed line that points to higher mean yield cross environments. Thus, the maximum grain yield was MABK181262, followed by MABK181261, MABK181259, and so on. The acute angle between MABK181262 and MABK181259 indicates that these two genotypes respond similarly in all environments, and the difference between them is proportional. Whereas, an obsute angle (e.g., MABK181261 vs BH660) indicates that the genotypes reacted inversely, with the MABK181261 outperforming the BH660 and vice versa. The difference in performance between genotypes MABK181261 and MABK181262, MABK181253 and MABK181251, and MABK181254 and BH660 in the respond environment was due to $\mathrm{G} \times \mathrm{E}$, where the genotypes were presented at right angles. AEC ordinate is the double arrowed line. It indicates a higher level of variability (poor stability in both directions). As a result, G1 was extremely stable, whereas MABK181259 was extremely unstable.

\section{Conclusion}

Identifying stable, high-yielding maize hybrids in multi-environment trials is critical to the success of commercial hybrids in Ethiopian highland transitional agroecology. In fact, all genotypes evaluated in representative of locations for this agroecology had higher grain yield advantages than the best commercial check (BH661) except one genotype. According to the GGE biplot model, only the Bako environment was chosen for both representative and discriminating genotype selection, indicating that it is an appropriate environment for selecting generally adapted genotypes. The test environment was divided into three mega environments by polygon views: Bako, Pawe, and Haromaya. The biplot's rays divided the plot into six sections, with four environments appearing in one sector and one appearing in a different sector. Seven genotypes which had different high yielding vertex with the longest vectors are located at the polygon's corner of vertex sector. In comparison to other hybrids, these genotypes were among the most responsive to the environments in their respective directions. In fact, all genotypes evaluated in representative locations for this agroecology had higher grain yield

Page 8/15 
advantages than the best commercial check except one genotype. Overall, this study discovered the possibility of fast releasing and overtake of new maize hybrids for transitional high land agroecology of Ethiopia to exploits availability maize germplasm to maximize production. The best candidate genotype, MABK181261 is a stable and high-yielding product. It is recommended for release as a commercial hybrid alternative after national variety verification trial in a high land transitional agroecology of Ethiopia. In addition, the parental lines of this genotypes can be used to enhance germplasm of opposite heterotic group in maize breeding for East Africa.

\section{Abbreviations}

GY: grain yield, G, genotype, E, environment, G x E interaction of genotype by environment, PC principal component, NPS nitrogen, phosphorous, sulfur, BH Bako Hybrid

\section{Declarations}

Acknowledgment: We thank researchers and technicians from collaborative research center from Pawe, Hawasa, Pawe, Haramaya and F/Selam for experimental management and data collection.

Authors' Contributions: Concept and proposal development: GG, BA, DC and TC. Proposal Editing: GG, AN, ZT and. Conducted experiment, Data organized and analyzing: GG, SO and BG. First draft result developed: GG, BA and ZT. Final version of writing and edition: GG, AN, TC and BA. "All authors have read and approved the manuscript".

Availability of data: The data sets generated and analyzed during the current study are available in the supplementary tables.

Funding: This research experiment was financially funded by Ethiopian government through Ethiopian Institute of Agricultural Research (EIAR) for Bako National Maize Breeding Research to evaluate national variety trials over locations of 2017/2018.

Ethics approval and consent to participate: All genetic material of maize inbred lines were obtained from EIAR, Bako National Maize Research Center (BNMRC) which is public research and used for this research experiment. All those inbred lines are freely available at BNMRC.

Consent for publication: Not applicable.

Competing Interests: The authors declare that they have conflict interests.

\section{References}

1. Mushayi, M., Shimelis, H., Derera, J. et al. Multi-environmental evaluation of maize hybrids developed from tropical and temperate lines. Euphytica 216, 84 (2020). https://doi.org/10.1007/s10681-020-02618-6

2. Alphonse Nyombayire, John Derera, Julia Sibiya, Claver Ngaboyisonga (2018). Genotype x Environment Interaction and Stability Analysis for Gran Yield of Diallel Cross Maize Hybrids Across Tropical Medium and Highland Ecologies. Journal of Plant Sciences. Vol. 6, No. 3, 2018, pp. 101-106. doi: 10.11648/j.jps.20180603.14

3. Li Z, Coffey L, Garfin J, Miller ND, White MR, Spalding EP, et al. (2018) Genotype-by-environment interactions affecting heterosis in maize. PLoS ONE 13(1): https://doi.org/ 10.1371/journal.

4. Y Matana, Miftahorrachman1, M Nur and M R Romadhon (2020). Stability of fruit and bunch of mapanget tall and Indonesia coconut hybrid with several planting distance using AMMI model and GGE biplot analysis. Earth and Environmental Science 418 (2020) 012034

5. C. E. Eze . R. O. Akinwale . S. Michel . H. Bu"rstmayr (2020). Grain yield and stability of tropical maize hybrids developed from elite cultivars in contrasting environments under a rainforest agro-ecology. Euphytica (2020) 216:89 https://doi.org/10.1007/s10681-02002620-y(01234567890.,--volv() 01234586970),--volv)

6. Badu-Apraku B, Fakorede MAB, Oyekunle M, Yallou GC, Obeng-Antwi K, Haruna A, Usman IS, Akinwale RO (2015b) Gains in grain yield of early maize cultivars developed during three breeding eras under multiple environments. Crop Sci 55:527-539. https://doi.org/10.2135/cropsci2013.11.0783

7. Badu-Apraku B, Annor B, Oyekunle M, Akinwale RO, Fakorede MAB, Talabi AO, Akaogu IC, Melaku G, Fasanmade Y (2015a). Grouping of early maturing quality protein maize inbreds based on SNP markers and combining ability under multiple environments. Field Crops Res.183:169-183 
8. BRANKOVIĆ-R. D, VOJKA BABIĆ1, Zdenka GIREK2, Tomislav ŢIVANOVIĆ3, Aleksandar RADOJĈIĆ4, Milomir FILIPOVIĆ1, Jelena SRDIĆ1. Evaluation of maize grain yield and yield stability by AMMI analysis. GENETIKA, Vol. 50, No3, 1067-1080, 2018

9. Emily E. Oldfield1, Mark A. Bradford1, and Stephen A. Wood1 (2019). Global meta-analysis of the relationship between soil organic matter and crop yields. Soil, 5, 15-32, 2019 https://doi.org/10.5194/soil-5-15-2019

10. Bocianowski, J., Niemann, J. \& Nowosad, K.(2019). Genotype-by-environment interaction for seed quality traits in interspecific crossderived Brassica lines using additive main effects and multiplicative interaction model. Euphytica 215, 7 (2019). https://doi.org/10.1007/s10681-018-2328-7

11. Workie Anley. "Genotype X environment interaction of maize (Zea mays L.) across North Western Ethiopia", Journal of Plant Breeding and Crop Science, 2013

12. Zobel RW, MJ Wright, and HG Gauch HG.1988 Statistical analysis of a yield trial. Agron. J. 80: 388-39

13. Getachew Gemechu and Ngozi E. Abu (2020). Combining ability of maize inbred lines (Zea mays L.) for yields in mid altitude subhumid Agroecology of Ethiopia. Academic Journal of Plant Sciences Vol. 14(6), pp. 231-242. DOI: 10.5897/AJPS2019.1908 Article Number: 62E097064068 ISSN 1996-0824

14. Legesse Wolde, Tolera Keno, Berhanu Tadesse, Gezahegn Bogale, Adefris T/Wold, Beyene Abebe (2018). Mega-Environment Targeting of Maize Varieties using Ammi and GGE Bi-Plot Analysis in Ethiopia. Ethiop. J. Agric. Sci. 28(2) 65-84 (2018)

15. Demissew Abakemal, Hussein Shimelis and John Derera (2018). Genotype-by-environment interaction and yield stability of quality protein maize hybrids developed from tropical highland adapted inbred lines. Euphytica. DOI 10.1007/s10681-016-1673-7

16. Wende Mengesha . Abebe Menkir . Silvestro Meseka . Bunmi Bossey . Afolabi . Juan Burgueno . Jose Crossa (2019). Factor analysis to investigate genotype and genotype 3 environment interaction effects on pro-vitamin A content and yield in maize synthetics. Euphytica (2019) 215:180.

17. Nzuve F, Githiri S, Mukunya DM, Gethi J (2013) Analysis of genotype nine environment interaction for grain yield in maize hybrids. J Agric Sci 5:75-85.

18. Kebede Dessalegn, Dagnachew Lule, Girma Mengistu, Kassa Mamo, Chemeda Birhanu, Girma Chemeda and Gudeta Bedada (2019). Genotype by Environment Interaction and Grain Yield Stability Analysis for FingerMillet (Eleusine coracana (L.) Gaertn) Genotypes from Western Oromia Ethiop. J. Crop Sci. Vol 6 No.1 $2018: 119-133$

19. Esayas Tena, Frehiwot Goshu, Hussein Mohamad, Melaku Tesfa, Diribu Tesfaye \& Abebech Seife I (2019). Genotype x environment interaction by AMMI and GGE-biplot analysis for sugar yield in three crop cycles of sugarcane (Saccharumofficinirum L.) clones in Ethiopia, Cogent Food \& Agriculture, 5:1, 1651925 https://doi.org/10.1080/23311932.2019.1651925

20. Yan W and NA Tinker (2006). Bi-plot analysis of multi-environment trial data: Principles and application. Canadian J. of P. Sci. 86: 623-645

21. Yan W, MS Kang, MAS Woods, and PL Cornelius (2007). GGE Bi-plot Vs. AMMI Analysis of Genotype-by environment data. Crop Sci., 47: 643-655

22. Yan W, LA Hunt, Q Sheng, and Z Szlavnics (2000). Cultivar Evaluation and Mega-environment Investigation Based on the GGE Biplot. Crop Sci., 40: 597-605.

23. Hortense Noëlle Apala Mafouasson , Vernon Gracen , Martin Agyei Yeboah , Godswill Ntsomboh-NtsefongID , Liliane Ngoune Tandzi and Charles Shelton Mutengwa (2018). Genotype-by-Environment Interaction and Yield Stability of Maize Single Cross Hybrids Developed from Tropical Inbred Lines. Agronomy V.8, 62; doi:10.3390/agronomy8050062

24. Yan W and MS Kang (2003). GGE Bi-plot Analysis: A Graphical Tool for Breeders, Geneticists, and Agronomists. CRC Press. Boca Raton, FL, P.288.

25. Wender Santos Rezende, Yoseph Beyene, Stephen Mugo, Eric Ndou, Manje Gowda, Julius Pyton Sserumaga, Godfrey Asea, Ismail Ngolinda, McDonald Jumbo, Sylvester O. Oikeh, Michael Olsen, Aluízio Borém, Cosme Damião Cruz, Boddupalli M. Prasanna. Performance and yield stability of maize hybrids in stress-prone 07 - environments in eastern Africa. The crop journal 107-118.

26. Saleem R, M Ashraf, IA Khalil, MA Anees, HI Javed, and A Saleem (2016). GGE Bi-plot Analysis: Windows Based Graphical Analysis of Yield Stability and Adaptability of Millet Cultivars Across Pakistan. Academia Journal of Biotechnology 4: 186-193

27. Dagnachew Lule, Kassahun Tesfaye, and Girma Mengistu (2014).Genotype by environment interaction and grain yield stability analysis for advanced triticale ( $x$. triticosecale wittmack) genotypes in western Oromia, Ethiopia. SINET: Ethiop. J. Sci., 37(1):63-68

28. Ndlala, Lucia Zinzi (2018). Evaluation of early maturing maize (zea mays I.) hybrids for multiple-stress tolerance. MSc. Thesis. https://researchspace.ukzn.ac.za/handle/10413/18159

Page $10 / 15$ 
29. Dao, A., Alvar-BeltrÃin, J., Guira, A., NÃ®bĩ̃®, L., Gnanda, A., \& Sanou, J. (2020). Biplot analysis of test environments of quinoa (Chenopodium quinoa Willd.) in Burkina Faso. African Journal of Plant Science, 14(9), 358-371.

https://doi.org/10.5897/AJPS2020.2038

30. Moges Firew Abel, Amsalu Berhanu, Tsegaye Dagmawit. "Additive main effects and multiplicative interaction (AMMI) and genotype main effect and genotype by environment interaction (GGE) biplot analysis of large white bean (Phaseolus vulgaris L.) genotypes across environments in Ethiopia", African Journal of Agricultural Research, 2019

\section{Figures}

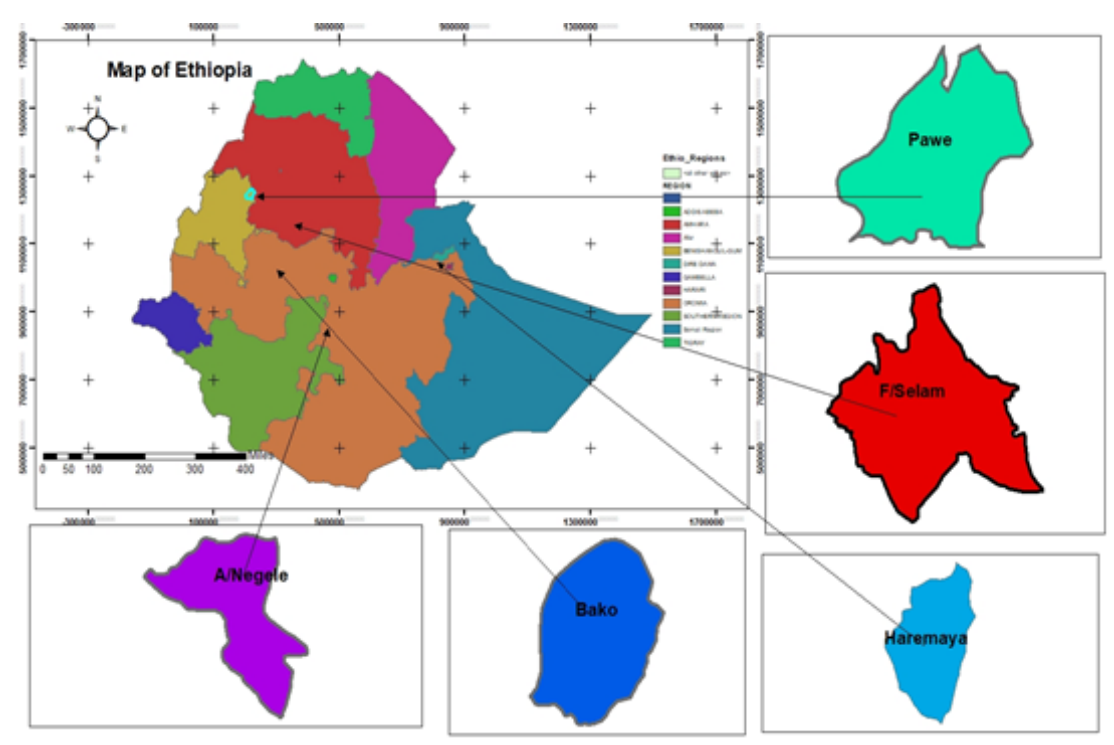

Figure 1

map of the locations (environments). After "Figure 1" 


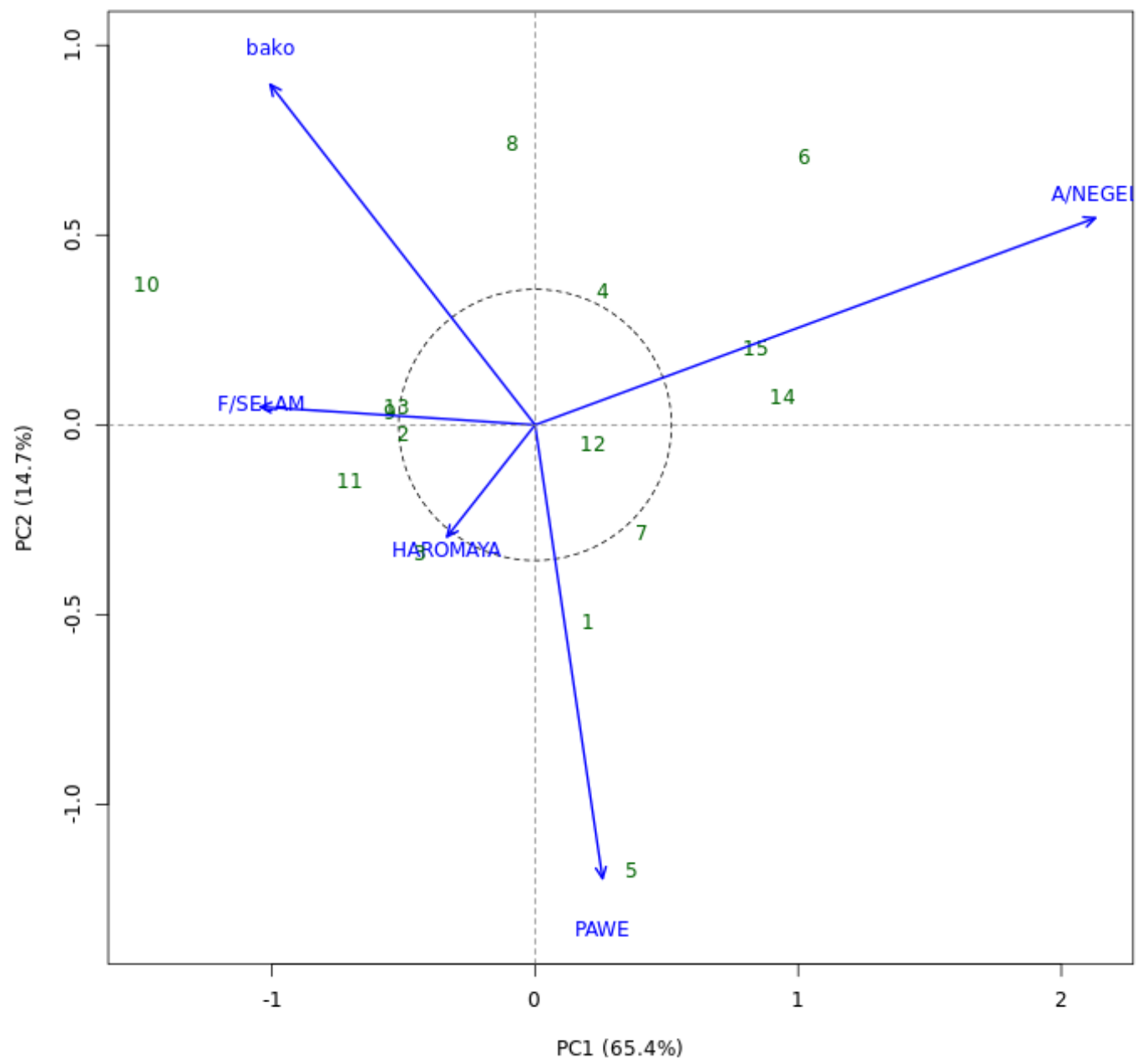

Figure 2

AMMI biplot: PC1 vs PC2. After "Figure 2" 


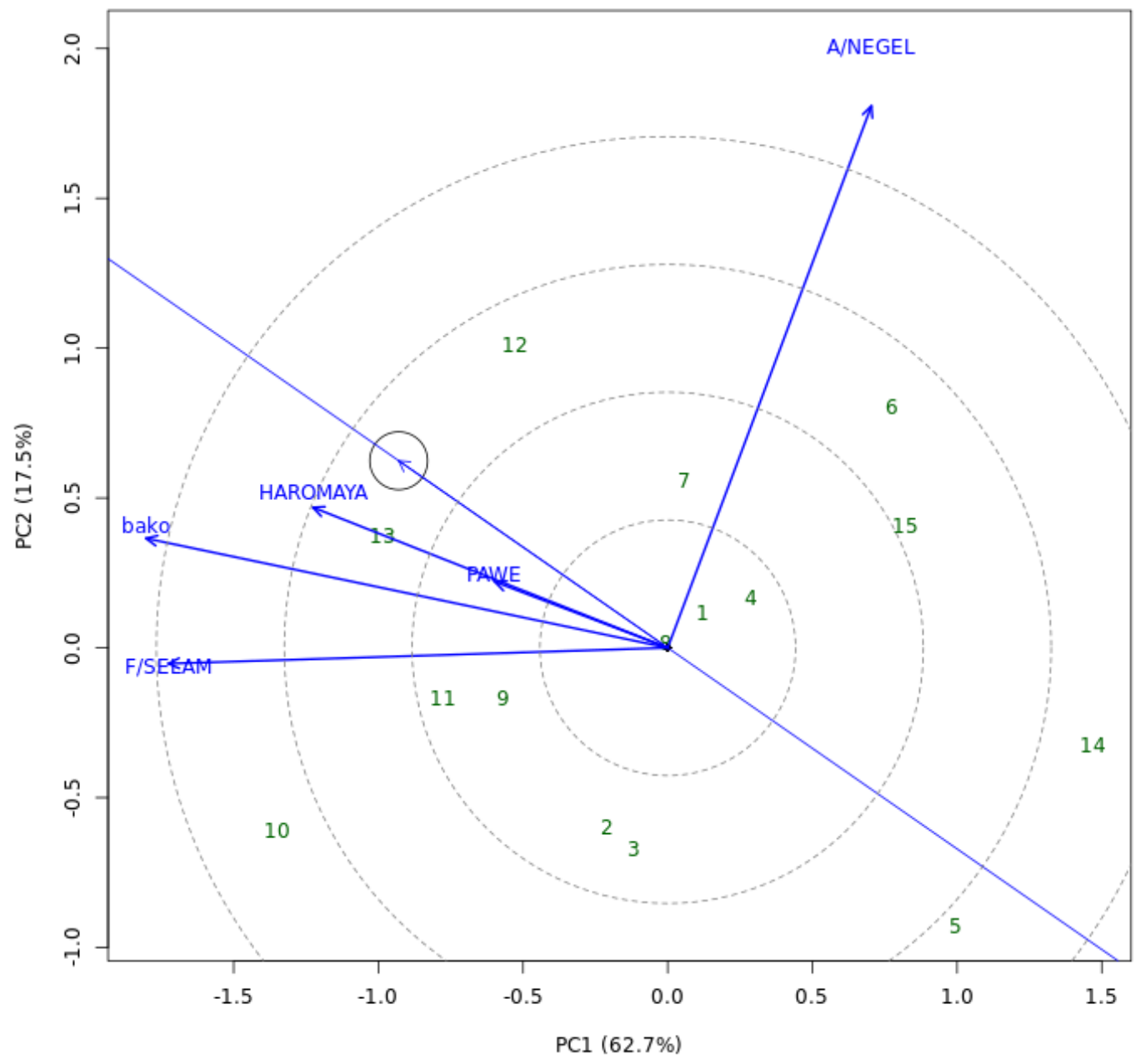

Figure 3

the GGE biplot's discrimination and representativeness view to show the test environments' discriminating ability and representativeness. After "Figure 3" 


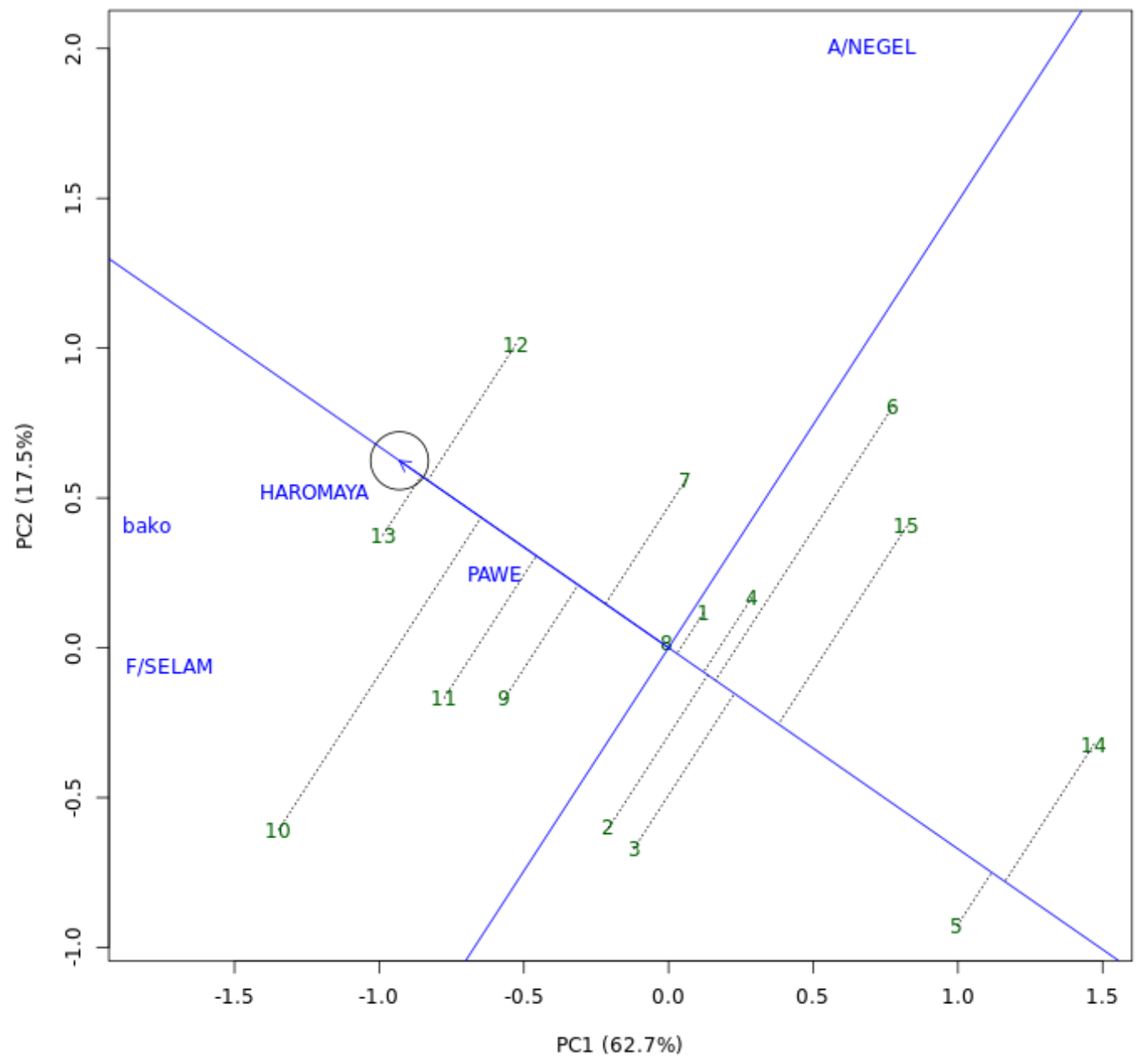

Figure 4

GGE biplot: Mean vs Stability. After "Figure 4" 


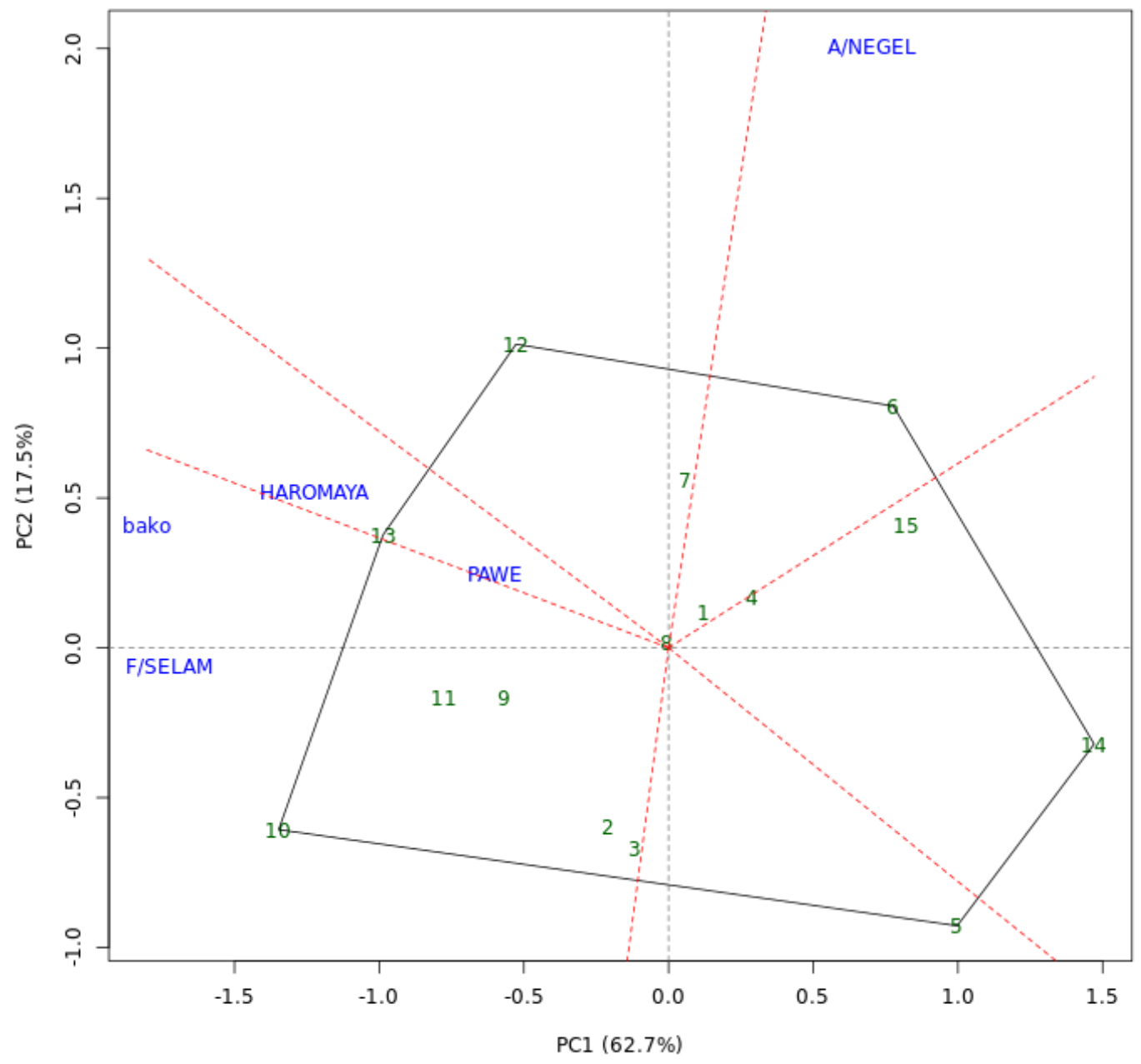

Figure 5

GGE biplot: which-won-where. After "Figure 5" 